\title{
Escritas Urbanas: sobre expressões artísticas na fronteira
}

\author{
Urban Writings: about artistic expressions in the border
}

Escrituras Urbanas: acerca de expresiones artísticas en frontera

\author{
Dra. Cláudia Mariza Mattos Brandão ${ }^{1}$
}

\begin{abstract}
Resumo
Este artigo tem por objetivo discutir sobre os resultados parciais de pesquisa desenvolvida no âmbito do projeto "O PARA-FORMAL NA FRONTEIRA BRASIL-URUGUAI: controvérsias e mediações no espaço público", cujas ações são dedicadas a dar voz e visualidade à "para-formalidade" nas cidades da fronteira-sul que fazem a divisa/união entre Brasil e Uruguai (Santana do Livramento-Rivera, Quaraí-Artigas, Jaguarão-Rio Branco, Barra do Quaraí-Bella Unión, Chuí-Chuy e Aceguá-Aceguá), relacionando as questões fronteiriças e a UFPel, a partir de cartografias urbanas e sociais. Trata-se, em especial, de analisar o inventário das produções fotográficas da pesquisadora, durante viagem pela região de fronteira entre Brasil e Uruguay, em março de 2016. Esse levantamento visual tem como foco as Escritas Urbanas, manifestações poéticas/artísticas que povoam muitas cidades contemporâneas, cujas significações surgem com a compreensão das intrínsecas relações entre o fenômeno (a cidade), o sujeito e seu contexto social e histórico. Tal apreciação contempla as escritas urbanas como construções estéticas e discursivas, cuja presença em território de fronteira dá visibilidade a questões particulares desses espaços. Além disso, os registros fotográficos manifestam-se como sínteses simbólicas da experiência vivida, devaneios poéticos acerca do espaço, como propõe Gaston Bachelard.
\end{abstract}

Palavras-Chave: Artes Visuais, Escritas Urbanas, Fronteira, História.

\section{Resumen}

Este artículo tiene como objetivo discutir los resultados parciales de una investigación desarrollados en el proyecto "O PARA-FORMAL NA FRONTEIRA BRASIL-URUGUAI: controversias e mediações no espaço público", cuyas acciones están direccionadas en dar voz y visualidad "para-formal"en las ciudades de la frontera sur que están en la frontera/unión entre Brasil y Uruguay (Santana do Livramento-Rivera, Quaraí-Artigas, Jaguarão-Río Branco, Quaraí-Bella Unión-bar, Chuí-Chuy y Aceguá-Aceguá), relacionando los asuntos fronterizos y UFPel, partiendo de cartografías urbana y sociales. En especial se trata de analizar el inventario de las producciones fotográficas de la investigadora durante un viaje por la región fronteriza entre Brasil y Uruguay en marzo del 2016. Esta encuesta visual tiene foco en las escrituras urbanas, manifestaciones poéticas /artísticas que habitan muchas de las ciudades contemporáneas, cuyas significaciones surgen con la comprensión de la relación intrínseca entre el fenómeno (la ciudad), el sujeto y su contexto social e histórico. Esa apreciación contempla las escrituras urbanas como construcciones estéticas y discursivas, cuya presencia en el territorio fronterizo da visibilidad a las cuestiones particulares de dichos espacios. Además de eso, los registros fotográficos se manifiestan como síntesis simbólica de la experiencia vivida, ensueños poéticos sobre el espacio, según lo propuesto por Gaston Bachelard.

Palabras claves: Artes Visuales, Escrituras Urbanas, Frontera, Historia.

\section{Abstract}

1 Doutora em Educação; Universidade Federal de Pelotas - UFPel; Pelotas, Rio Grande do Sul, Brasil. attos@vetorial.net 
This paper aims at discussing partials results of a study carried out in the project "O PARA-FORMAL NA FRONTEIRA BRASIL-URUGUAI: controversias e mediações no espaço público"whose actions focus on temporary objects and trades that provoke detours in a city systematically. This Project was conducted in cities that share borders between Brazil and Uruguay (Santana do Livramento-Rivera, Quaraí-Artigas, Jaguarão-Río Branco, Quaraí-Bella Unión-bar, Chuí-Chuy y Aceguá-Aceguá), and relates borders issues and the UFPel', located in Pelotas, RS, Brazil, based on urban and socials cartographies. This paper describes the analysis of the researcher's photographic productions gathered in a trip to the border region between Brazil and Uruguay, in March 2016. This visual collection focuses on "urban writings", which are poetic/artistic manifestations that occupy many contemporary cities. Their signification arises from the understanding of the intrinsic relations among the phenomenon (the city), the subject and his/her social and historical context. Urban writings are seen as aesthetic and discursive constructions, whose presence in the border region highlights issues which are specific to these places. Besides, the photographic records became a symbolic synthesis of a life experience, poetic reveries of the space, as proposed by Gaston Bachelard.

Keywords: Visual Arts, Urban Writings, Border, History.

\section{Introdução}

A que lugar eu pertenço? A globalização nos leva a re-imaginar a nossa localização geográfica e geocultural. As cidades, e, sobretudo, as mega-cidades são lugares onde essa questão se torna intrigante. Ou seja, espaços onde se apaga e se torna incerto o que antes se entendia por "lugar". Não são áreas delimitadas e homogêneas, mas espaços de interação em que as identidades e os sentimentos de pertencimento são formados com recursos materiais e simbólicos de origem local, nacional e transnacional (CANCLINI, 2003, p.153).

Se aplicarmos o pensamento de Canclini às cidades localizadas em regiões fronteiriças a questão ganha novos contornos. Isso, pois tais espaços já trazem em si a complexidade das múltiplas misturas étnicas que aí se encontram, formando um caldo cultural ímpar.

Na busca de desvelar novas significações desses espaços, procurando outros modos de entender o mundo, pode-se dizer que a apreensão dos contextos sociais pela via do olhar estético-crítico é um meio para a construção de um repertório de conhecimentos significativos, capazes de tornar os envolvidos no processo em sujeitos conscientes da realidade e do seu grupo social. Sendo assim, desenvolver as capacidades sensíveis possibilita que se perceba o mundo através de suas manifestações cotidianas, apreendendo as nuances dos processos sociais e históricos que permeiam os espaços urbanos.

O projeto "Para-Formal na Fronteira" (UFPel/CNPq), coordenado pelo Prof. Dr. Eduardo Rocha, da Faculdade de Arquitetura e por esta pesquisadora, busca dar voz e visualidade às para-formalidades na região da fronteira Brasil-Uruguay, desvelando através da percepção sensível os meandros desses territórios. Consideramos que os lugares "paraformais" são aqueles não regulados, ditos "anarquistas", nos quais são desenvolvidas atividades que subvertem a sua natureza tradicional, transformando significativamente o espaço urbano e caracterizando-o através das tensões que o geram. 

e-ISSN 2016/Atual: 2525-7870 | e-ISSN 2015/2016: 2447-018X

As ações metodológicas da investigação foram coroadas com a realização de uma viagem através da referida zona de fronteira, entre os dias 14 e 19 de março de 2016, quando foram visitadas as cidades de Santana do Livramento-Rivera, Quaraí-Artigas, Jaguarão-Rio Branco, Barra do Quaraí-Bella Unión, Chuí-Chuy e Aceguá-Aceguá, com financiamento do Conselho Nacional de Desenvolvimento Científico e Tecnológico (CNPq). Neste período, vinte e dois pesquisadores, de diferentes áreas de formação, tiveram a oportunidade de se dedicar a temas específicos de interesse pessoal de cada participante. Assim, com a caracterização multidisciplinar do grupo, ficou mais fácil contemplar diferentes aspectos das para-formalidades fronteiriças.

Este trabalho tem por objetivo discutir sobre um dos tópicos investigados, as escritas urbanas nas cidades visitadas, analisando as semelhanças e diferenças encontradas, com relação à presença dessas manifestações em duas cidades específicas: Pelotas e Montevidéu. Cabe ressaltar que a análise dos dados está em processo, portanto, o texto abordará resultados parciais, considerando que o projeto se estende até 2018, e outras cidades/fronteiras serão analisadas.

Durante a estada em cada cidade foram fotografados graffiti e pixos, e tal acervo está sendo analisado em si e em comparação aos acervos da pesquisadora, com relação às cidades parâmetros supracitadas. Considero importante ressaltar que teóricos como Johannes Stahl (2009), dentre outros, consideram que "graffiti" é sinônimo de "pixo", entretanto, o senso comum costuma diferenciar as produções com apuro estético do graffiti, das escritas nem sempre decifráveis por todos dos pixos. Neste trabalho ambos serão tratados como escritas urbanas, as quais produzem discursos imagéticos passíveis de interpretação.

Buscando a compreensão de tais escritas em regiões fronteiriças e analisando-as como expressões das diferentes dinâmicas organizacionais de tais espaços, se considera a complexidade dessas regiões, cujas identidades culturais na atualidade são forjadas a partir da presença de indígenas, brasileiros, uruguaios, espanhóis e outros estrangeiros das mais variadas nacionalidades. Logo, a tensão do sincrônico que emerge destes produtos da vida cultural, do multiculturalismo decorrente da amálgama de diferentes culturas que convivem nesse espaço geográfico, dá visibilidade às especificidades linguísticas resultantes das intervenções dos habitantes da fronteira, suas práticas econômicas lícitas ou ilícitas, suas manifestações religiosas e culturais. Características essas, que resultam dos povos que fizeram e fazem da fronteira Brasil-Uruguai uma região em permanente busca de interpretação para sua(s) identidade(s). 


\section{Sobre Escritas Urbanas}

Guy-Ernest Debord (1931-1994), o fundador da Internacional Situacionista, é considerado uma das grandes referências do pensamento da segunda metade do século XX. Ele defendia a ideia de que não basta ao pensamento buscar a sua realização, pois antes é preciso que a realidade procure o pensamento, crítico e reflexivo. E, nesse sentido, Debord considerava que a classe trabalhadora era naquele momento, a década de 1960, legatária "da arte moderna e da primeira crítica consciente da vida moderna", sendo que "a criatividade liberada na construção de todos os momentos e eventos da vida é a única poesia" reconhecível (BADERNA, 2002, p.56). Em um dos documentos divulgado pelo Comitê de Ocupação da Universidade Autônoma e Popular da Sorbone, datado de 16 de maio de 1968, durante as ações do MAIO DE 68, encontramos uma lista de "SLOGANS PARA SEREM DIFUNDIDOS POR TODOS OS MEIOS: em panfletos, falando em microfones, tiras de quadrinhos, músicas, graffiti..." (BADERNA, 2002, p.131). A inclusão do graffiti como meio de divulgação das palavras revolucionárias ressalta-o como expressão transgressora, fruto da experiência participativa nas cidades e da corporeidade dos sujeitos. Trata-se, portanto, de assumir o corpo humano como resultado de acontecimentos, sentidos, prazeres, expressões, valores e discursos, e do seu papel determinante na história das ideias, pois a corporeidade implica na sua inserção num mundo significativo, em relação dialética consigo mesmo, com os outros corpos expressivos e o mundo ao redor.

Vemos, portanto, que a realidade concreta não se reduz a um conjunto de dados materiais ou de fatos isolados, que carecem somente de avaliações estatística e prognósticos técnicos. Ela está intrinsecamente relacionada às manifestações artísticas e culturais que permeiam nosso cotidiano, tais como o Graffiti/Pixação. Práticas essas, que manifestam, acima de tudo, a vontade dos indivíduos de se inserirem no mundo, marcando presença numa realidade que cada vez mais os condena à obscuridade. Como exemplos de "artes marginais", as escritas urbanas exercitam a comunicação e estabelecem uma relação interativa com o contexto sócio-histórico, se constituindo como meios de expressão espontâneos e autênticos e, como tal, um assunto que merece ser investigado. Isso, pois valorizar a observação do cotidiano significa reconhecer nele o substrato das atitudes sociais, reflexo de mentalidades e comportamentos.

Em tal processo, o exercício da contemplação possibilita a percepção das relações e inter-relações que constituem a vida social, ressaltando a importância da atividade simbólica para a compreensão de qualquer agregação social. Logo, discutir a cultura em regiões de fronteira pelo viés da sensibilidade ao visível colabora para a captação e maior entendimento 

e-ISSN 2016/Atual: 2525-7870 | e-ISSN 2015/2016: 2447-018X

da constituição do ser como parte integrante de um mundo de efeitos globais, pois "existe outro sentido que precede as palavras, o ato de ver que estabelece nosso lugar no mundo circundante” (BERGER, 1999, p.9).

O termo graffito (GITAHY, 1999, p. 13) deriva do vocábulo greco-latino "graphis", que significa escrever, desenhar, e se refere a inscrições ou desenhos datados de tempos remotos, toscamente riscados em rochas. No idioma italiano, a palavra deu origem a graffito (singular) e graffiti (plural), termo também utilizado para designar a técnica artística. E das inscrições paleolíticas, chegamos às cidades contemporâneas, muitas recobertas por uma "capa" que desvela a forma de ser de gerações:

Cobrimos assim o universo de nossos desenhos vividos. Esses desenhos não precisam ser exatos. Apenas é preciso que sejam tonalizados pelo modo de ser do nosso espaço interno. Mas que livro seria necessário escrever para esclarecer todos esses problemas! O espaço chama a ação, e antes da ação a imaginação trabalha. Ela ceifa e lavra (BACHELARD, 1993, p. 22).

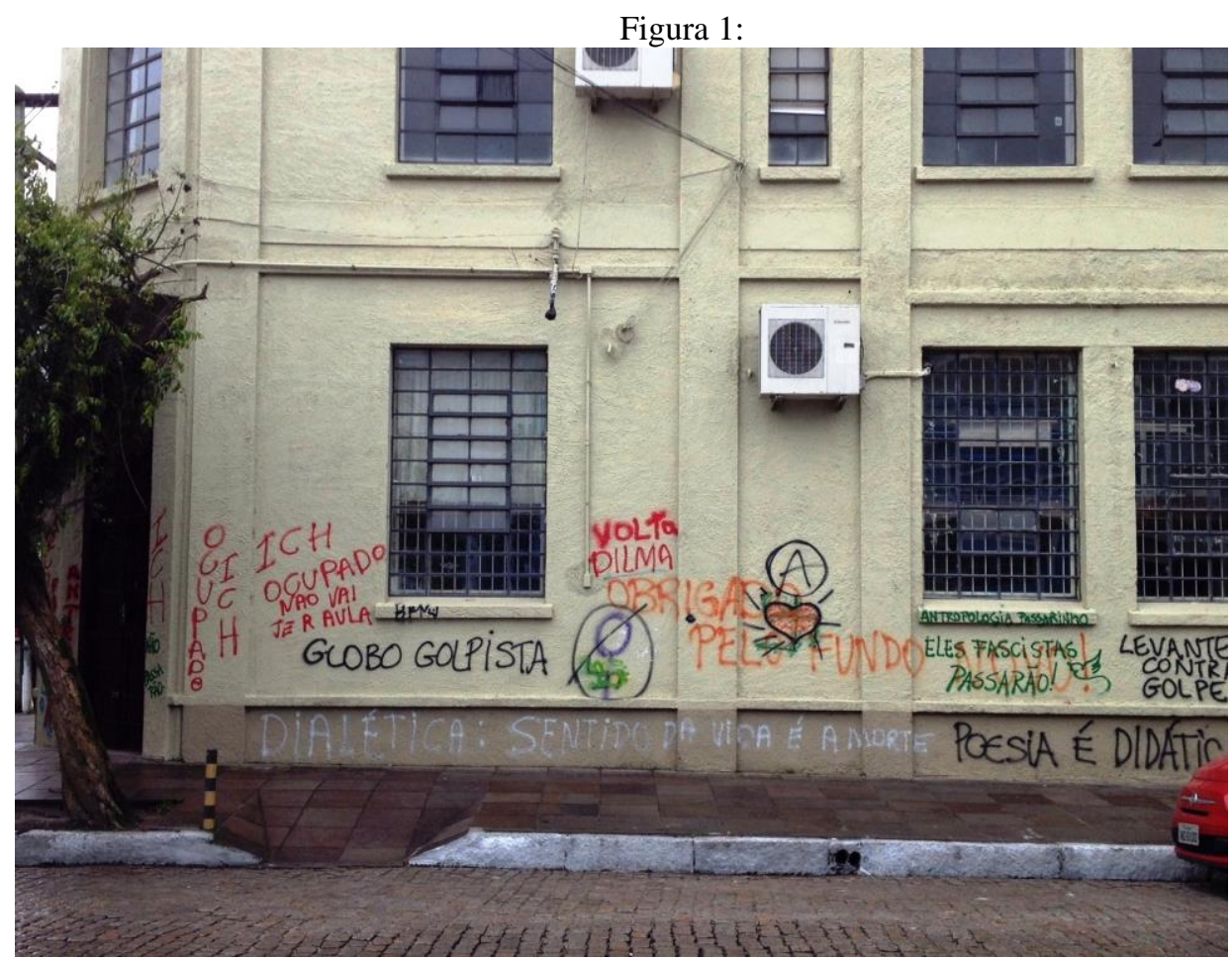

Autor, Instituto de Ciências Humanas (UFPel), fotografia digital, 2016.

Tanto na cidade de Pelotas (Figura 1), assim como na capital uruguaia Montevidéu (Figura 2), tais inscrições parecem multiplicar-se a cada dia, confirmando o pensamento de Bachelard de que a imaginação "ceifa e lavra" cada vez com mais intensidade os espaços urbanos contemporâneos. Para além das questões relativas à controversa estética e da ética com relação ao patrimônio público ou de outrem, elas são indicativas de espaços 

e-ISSN 2016/Atual: 2525-7870 | e-ISSN 2015/2016: 2447-018X

convulsionados por problemas sociais e políticos, e assim são analisadas na pesquisa ora apresentada. Nas duas cidades, parâmetros para a pesquisa, a presença maciça das escritas urbanas indica a importância de tentar-se desvelar suas mensagens truncadas, como resultado de vozes anônimas que geralmente buscam através dessas marcas identirárias darem visibilidade a suas inquietações.

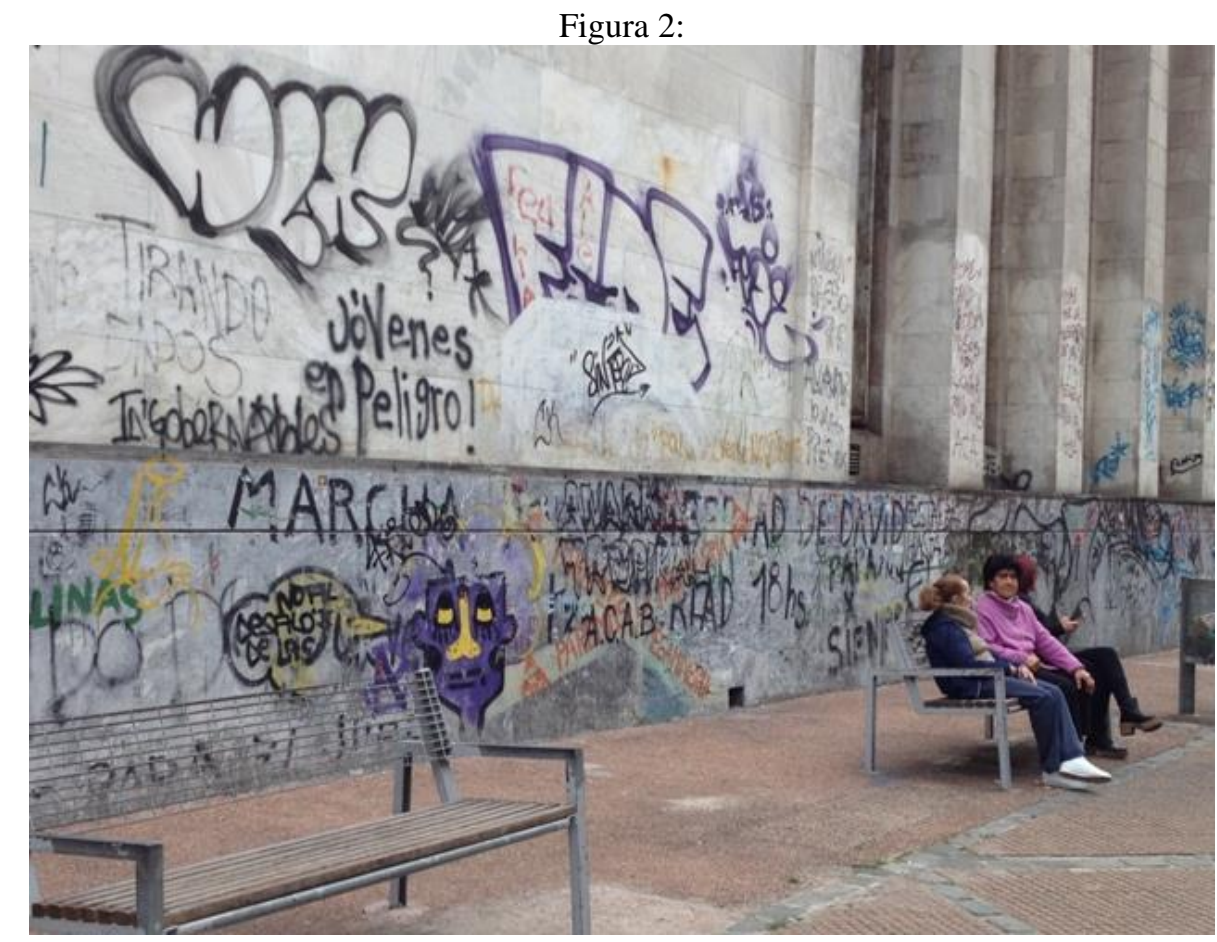

Autor, Universidad de Montevideo, fotografia digital, 2016.

Os situacionistas colocam o conhecimento da cidade "sob o signo da exploração psicogeográfica" (TACUSSEL in: GUTFREIND e SILVA, 2007, p.12), um termo que indica tanto a natureza objetiva do espaço, assim como, "a observação dos efeitos do meio geográfico sobre os comportamentos afetivos" (ibid., p.13). Tal pensamento nos leva a considerar o urbano como um lugar especial para o lúdico, que frutifica das ligações dinâmicas entre os sujeitos e os espaços. Portanto, se pensarmos sobre o que nos é apresentado pelas Figuras 1 e 2, é possível considerar que as escritas que tem como suporte os prédios das duas universidades estão diretamente relacionadas às experiências de quem ali convive.

Entretanto, sabemos bem que muitas vezes os transeuntes, que vivem em permanente estado de alerta, visam antes de tudo à sua própria sobrevivência. Eles geralmente percorrem suas trilhas sem olhar para a cidade, mergulhados em seus mundos particulares, muitas vezes entrincheirados nos ônibus ou nos automóveis. Assim, eles não têm mais tempo para perceber 

e-ISSN 2016/Atual: 2525-7870 | e-ISSN 2015/2016: 2447-018X

a cidade a partir de experiências sensoriais, permitidas pelas derivas participativas que constroem e reconstroem a cidade permanentemente. Submetidos ao rolo compressor homogeneizante das dinâmicas cotidianas, os passantes tornam-se agentes passivos em lugares nos quais o fato deveria se fundir à imaginação, fruto de relações particulares estabelecidas entre os indivíduos e os objetos através da interação criativa que deveria configurar a vida urbana.

Na contramão de tal realidade - do afastamento do cidadão do espaço urbano enquanto construção coletiva - é possível identificar as ações dos artistas grafiteiros/escritores urbanos. Para esses, a cidade se torna um palco e eles atores protagonistas ao invés de meros espectadores. Assim, a partir da experiência física da cidade, potencializada pela experiência sensorial e artística proporcionada pelas escritas urbanas, o espaço urbano é consagrado ao domínio da percepção estética, e como tal é percebido pela pesquisadora em suas deambulações pela fronteira Brasil - Uruguai.

Cabe também destacar que é possível considerar tais escrituras como traduções da sensação de fragmentação, efemeridade e mudança caótica, introduzidas na vida cotidiana pela modernidade. Sejam as formas criativas e estéticas, ou os pixos aleatórios, eles promovem uma resistência e provocam fissuras na percepção do urbano, fazendo com que tais espaços deixem de ser simples cenários e se transformem em palcos urbanos, lugares de expressão, crítica e reflexão:

(...) Bachelard não fala do espaço apenas diurnamente, enquanto categoria física e matemática, espaço neutro, impessoal; resgata, no nível do imaginário poético e filosófico, o espaço enquanto lugar: situado, singular, povoado por lembranças pessoais, sítio de experiências, colorido por emoções datadas. Esse espaço, que se desdobra e singulariza em casa, concha, ninho, cofre, gaveta..., é cenário da vida do corpo, morada de afetos, fonte de poiesis artística ou filosófica, fundamento da natureza enquanto paisagem (PESSANHA in: NOVAES, 1988, p.156).

Assim considerando, é possível perceber a paisagem urbana como uma construção simbólica que frutifica dos modos subjetivos de ver (BACHELARD, 1993). Portanto, apreender o espaço, está mais para o plano simbólico do que para o real observado. E é nesse universo de interferências dos seres humanos sobre o espaço, (re)construindo a paisagem, que demarco a importância das escritas urbanas.

\section{As Escritas Urbanas na fronteira Brasil - Uruguai}

Os símbolos que vemos na rua e nas paredes não estão em caso algum desvinculados do tempo a que dizem respeito. Quer seja sobre as ideias políticas, quer do que se entende como estético ou dos objectivos que se perseguem no momento, esses 
RELACult - Revista Latino-Americana de Estudos em Cultura e Sociedade

Revista Latinoamericana de Estudios en Cultura y Sociedad | Latin American Journal of Studies in Culture and Society V. 02, Ed. Especial, dezembro, 2016, p. 780-794| periodicos.claec.org e-ISSN 2016/Atual: 2525-7870 | e-ISSN 2015/2016: 2447-018X

símbolos dão-nos, com frequência, uma solução, antes de que aquilo que representam se transforme em bem comum da cultura oficial (STAHL, 2009, p.8).

Com base no pensamento de Stahl, é possível considerar a atividade criativa que tem como suporte o espaço urbano mais do que um expoente da criação artística, ela se apresenta como um importante indicador histórico. E no contexto histórico contemporâneo a presença dos artistas de rua e de suas criações é fundamental para que no corre-corre cotidiano possamos refletir sobre o mundo ao redor, uma proposta cara aos situacionistas.

As escritas urbanas são construções discursivas que combinam um alinhamento de interesses em determinado momento histórico, através das quais questões politicamente colocadas adquirem relevância, assumindo assim condições para a sua discussão e enfrentamento sob os pontos de vista científico e epistemológico. Como todo campo científico mediado por relações sociais, as contradições que caracterizam tais discursos se encontram presentes. Logo, analisar as relações estabelecidas no território fronteiriço entre Brasil e Uruguai abre um novo leque de possibilidades, outras lentes que nos revelam facetas peculiares dessa região.

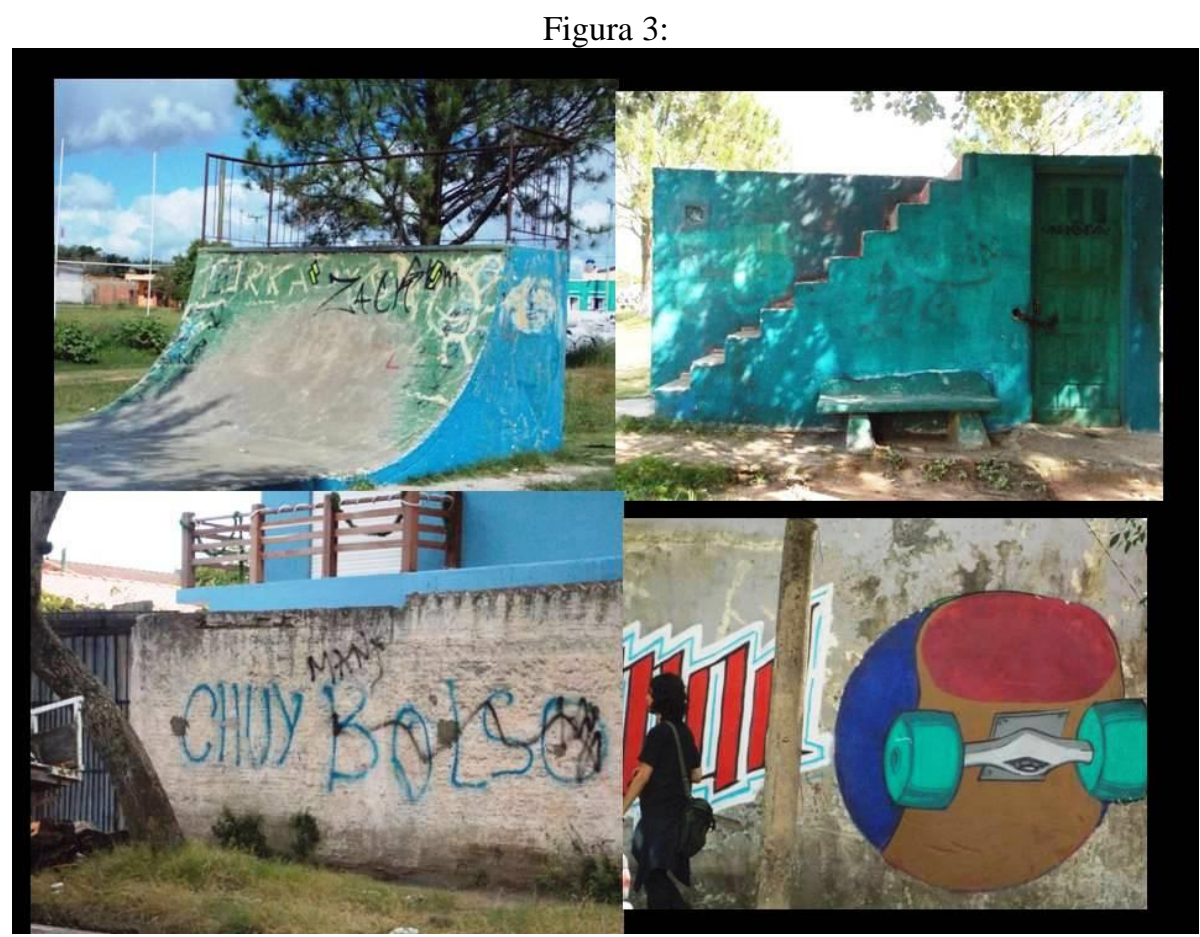

Autor, Chuí/Chuy, montagem fotográfica, 2016.

Partindo da experiência com as cidades parâmetros, Pelotas e Montevidéu, o deslocamento pelas doze cidades visitadas na linha de fronteira foi surpreendente, apresentando particularidades que acenam para as características desses espaços. As duas 

e-ISSN 2016/Atual: 2525-7870 | e-ISSN 2015/2016: 2447-018X

primeiras, Chuí e Chuy (Figura 3 - superior), já mostraram algumas peculiaridades. Na cidade do Chuí foram identificados graffiti numa praça dedicada à prática do skate, um espaço cujos frequentadores já possuem uma relação mais próxima da prática artística, entretanto, fora dali nada foi encontrado. No Chuy (Figura 3 - inferior) alguns graffiti nas ruas identificam a prática realizada por artistas de rua da cidade de Pelotas. Além delas, localizamos algumas pixações de cunho político espalhadas pelos muros, embora o número não seja significativo, assim como em Montevidéu. As duas cidades tem um ritmo cotidiano agitado nas ruas centrais, em função do comércio nos free shops, entretanto, as ruas mais distantes são muito tranquilas, principalmente, do lado uruguaio.

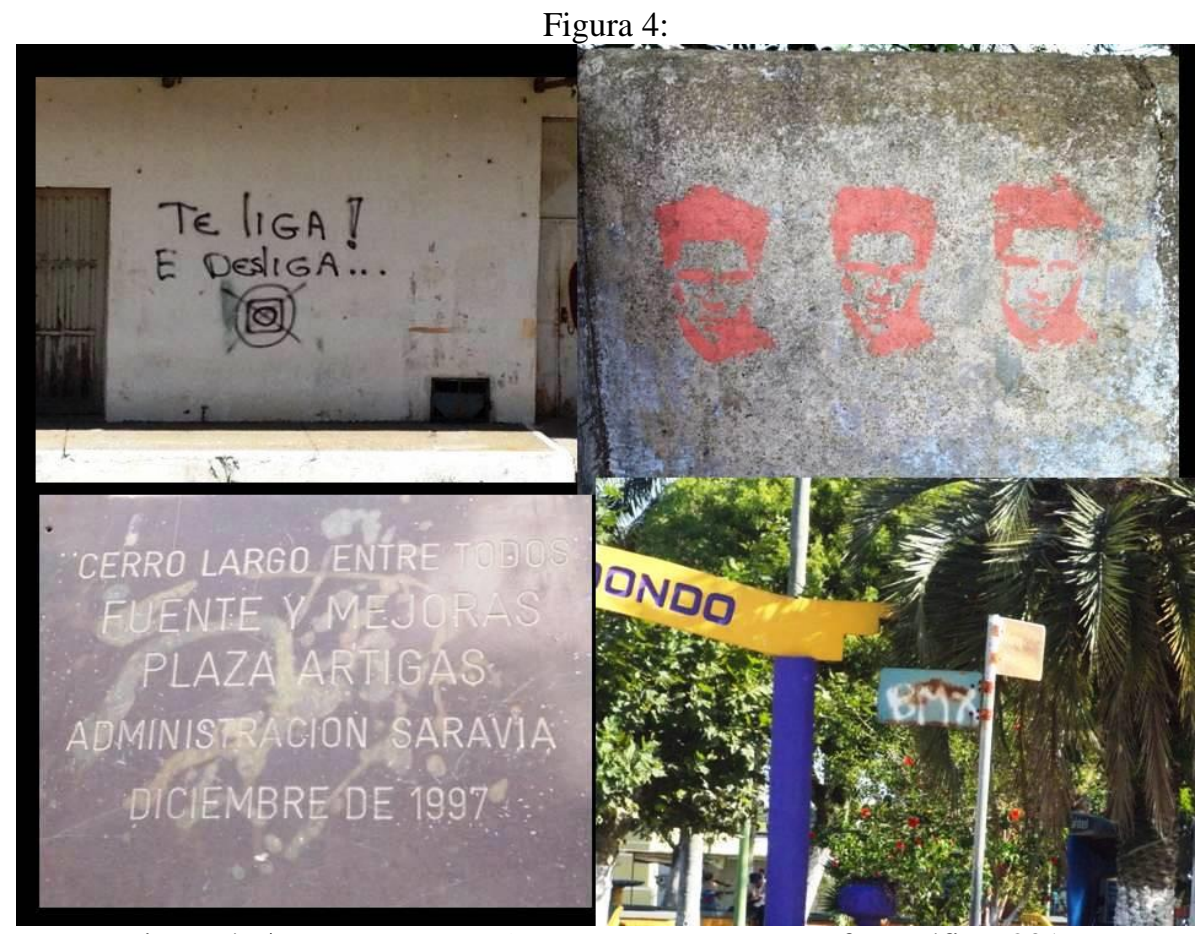

Figura 4: Autor, Jaguarão/Rio Branco, montagem fotográfica, 2016.

Em Jaguarão (Figura 4 - superior) encontramos alguns stencils (graffiti realizado com a utilização de molde vazado) na beira do rio, além de poucas pixações de cunho político. Segundo a declaração de uma moradora, as intervenções registradas só começaram a aparecer depois que a cidade recebeu estudantes universitários de outras cidades e estados, que chegam a Jaguarão para cursar Produção Cultural. Em Rio Branco (Figura 4 - inferior), uma cidade pacata e muito limpa, somente duas pequenas intervenções na Plaza Artigas, uma numa placa e outra num monumento, foram registradas. Soube por colegas que na antiga Estação de Trem da cidade tinha um vagão grafitado, assim como um que estava nas margens do rio, do lado de Jaguarão, que avistei do ônibus. 

e-ISSN 2016/Atual: 2525-7870 | e-ISSN 2015/2016: 2447-018X

Posso dizer que a Santana do Livramento (Figura 5 - superior) foi uma desagradável surpresa para o grupo de pesquisadores. Isso, pois encontramos uma cidade suja, mal conservada, na qual as fachadas históricas estão encobertas pelas placas comerciais. Outra particularidade é o volume do comércio de rua, informal. No entorno central encontramos muito pixo e nenhum graffiti. Já Rivera (Figura 5 - inferior), por sua vez, nos surpreendeu positivamente. Encontramos uma cidade bonita, limpa e arejada, com alamedas amplas e uma praça muito bem cuidada, bem diferente da de Jaguarão. Quanto à presença de escritas urbanas, algumas foram encontradas, mas em menor número. O que chamou a minha atenção foi uma inscrição semelhante à outra que registrei no Chuy: "Rivera Bolso" e "Chuy Bolso". Ou seja, alguém circulou por esses espaços deixando sua marca nos muros. Em todo o trajeto ao longo da linha de fronteira esse foi o único caso de deslocamento de um escritor de rua que identifiquei.

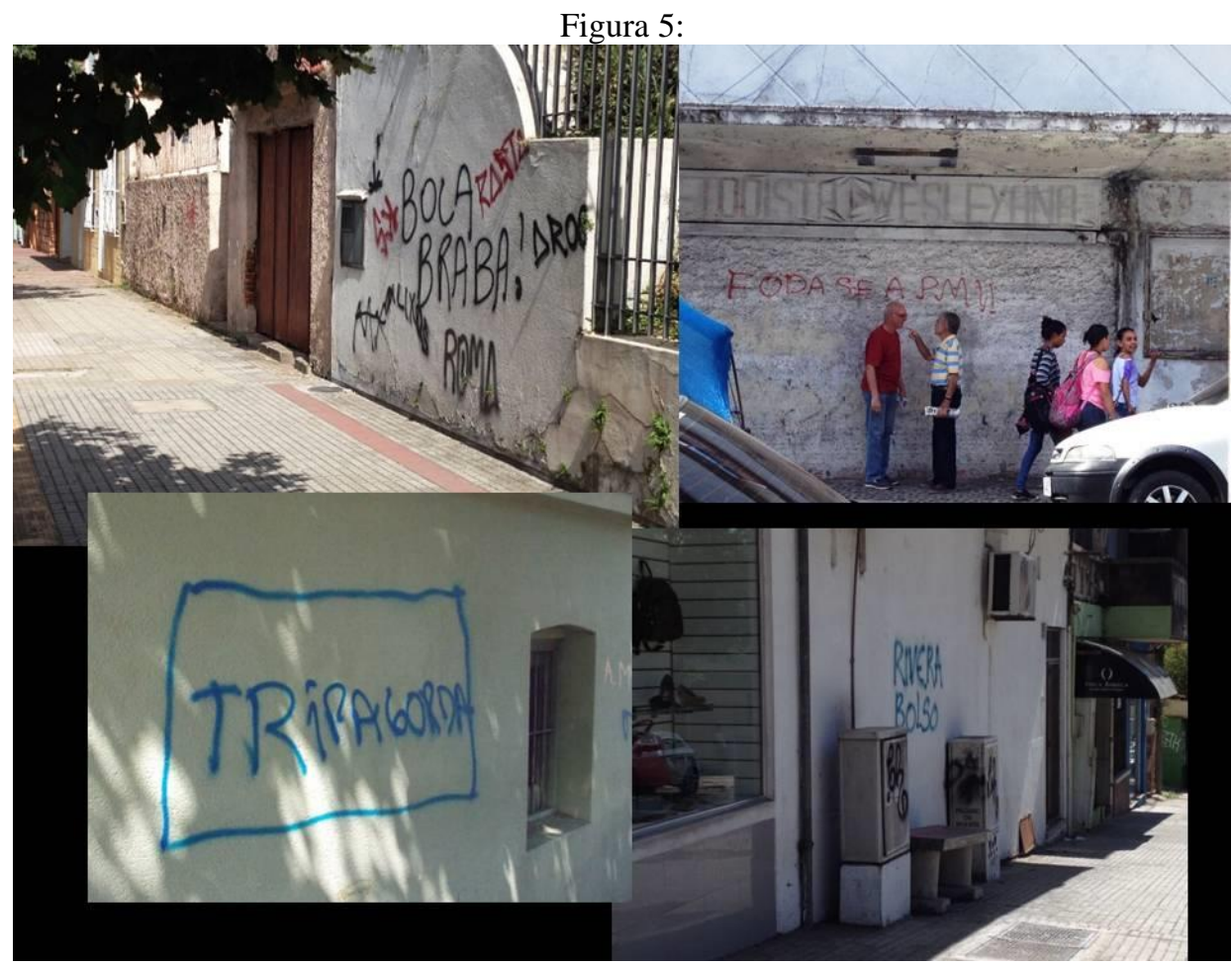

Autor, Santana do Livramento/Rivera, montagem fotográfica, 2016.

Em Quaraí (Figura 6 - superior) chegamos ao entardecer e seus habitantes já se preparavam para descansar. Descobrimos uma cidade pacata, com características conservadoras no que se refere ao comportamento de seus moradores. Nesse espaço, poucos foram os pixos encontrados, todos localizados na rua principal da cidade, sendo que algumas ruas do entorno central apresentam um ar rural, com muitas carroças e carros antigos 
RELACult - Revista Latino-Americana de Estudos em Cultura e Sociedade

Revista Latinoamericana de Estudios en Cultura y Sociedad | Latin American Journal of Studies in Culture and Society V. 02, Ed. Especial, dezembro, 2016, p. 780-794| periodicos.claec.org e-ISSN 2016/Atual: 2525-7870 | e-ISSN 2015/2016: 2447-018X

estacionados. Diferente das demais visitadas até então, Quaraí tem um ar de cidade "do interior".

Artigas (Figura 6 - inferior), por sua vez, é bem diferente. Uma cidade com ruas amplas e muito movimento, tanto de carros quanto de pessoas. E a diferença marcante entre as duas cidades provavelmente se explique pelo fato de que elas são as mais distantes uma da outra das cidades visitadas. Não localizei graffiti nos locais visitados, entretanto, na praça central, lugar de reunião dos jovens, os pixos proliferam.

\section{Figura 6:}

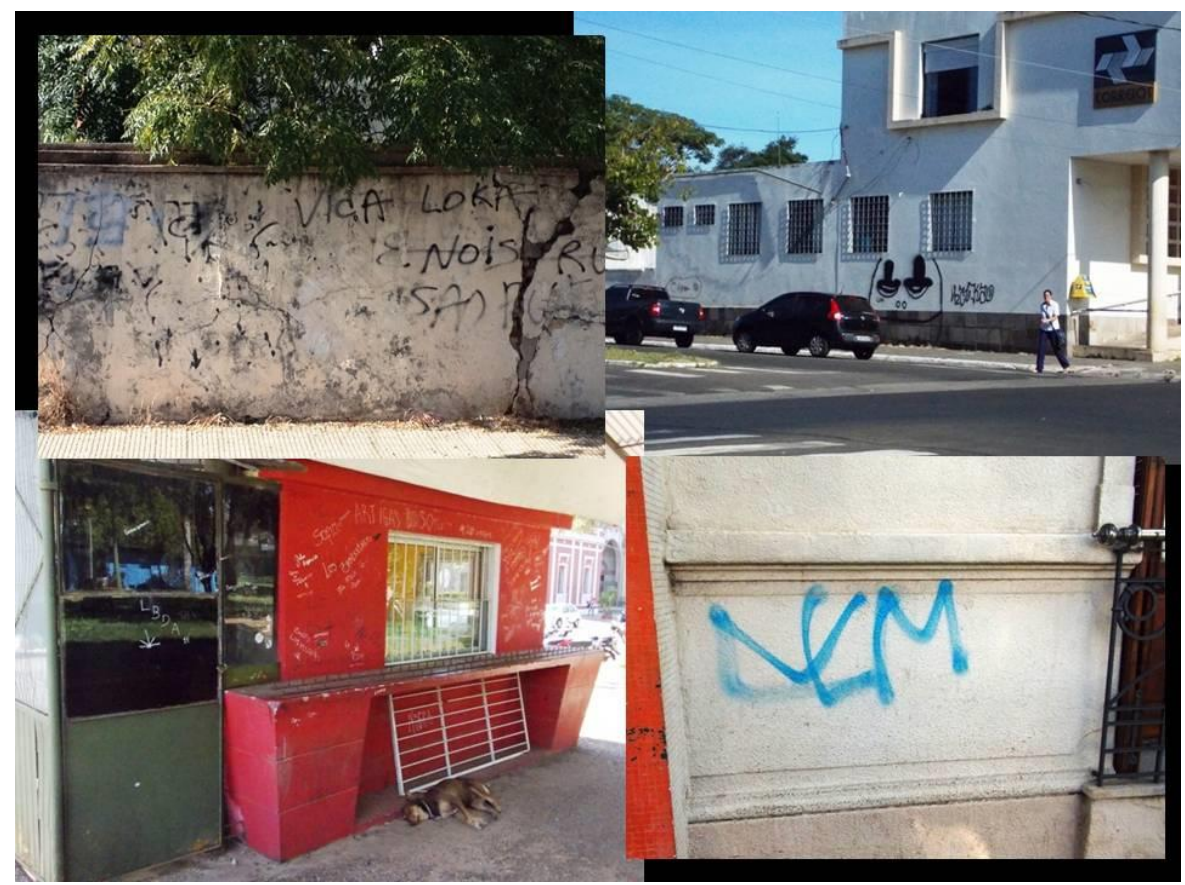

Autor, Quaraí/Artigas, montagem fotográfica, 2016

Figura 7: 
RELACult - Revista Latino-Americana de Estudos em Cultura e Sociedade

Revista Latinoamericana de Estudios en Cultura y Sociedad | Latin American Journal of Studies in Culture and Society V. 02, Ed. Especial, dezembro, 2016, p. 780-794| periodicos.claec.org e-ISSN 2016/Atual: 2525-7870|e-ISSN 2015/2016: 2447-018X

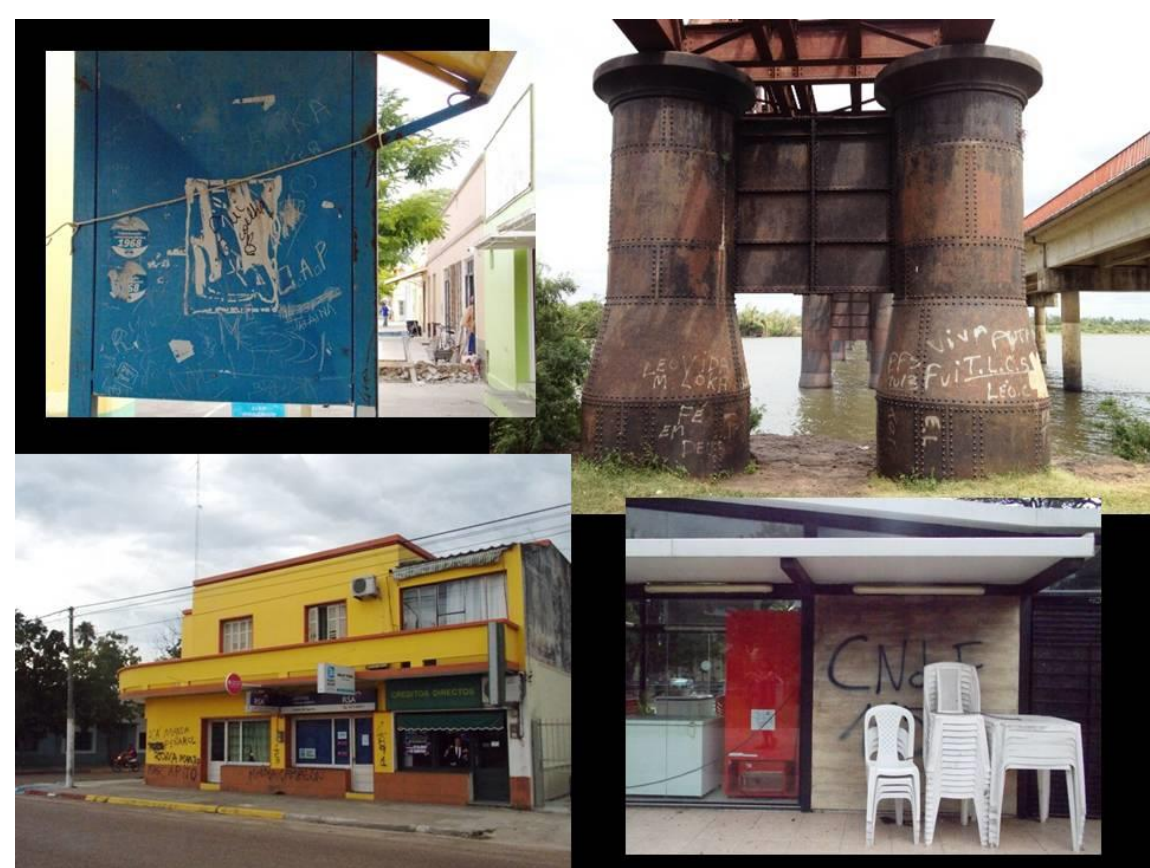

Autor, Barra do Quaraí/Bella Unión, montagem fotográfica, 2016.

Barra de Quaraí (Figura 7 - superior) em muito se assemelha à Quaraí, embora seja bem menor. Uma pequena cidade, com uma rua central onde se distribui o comércio local em seus pequenos estabelecimentos, que em nada lembra uma cidade "de fronteira". Pode-se dizer que de todas as visitadas é a mais interiorana, sem ser rural. A menor de todas, com 4000 habitantes, Barra do Quaraí tem pouquíssimas inscrições, sendo que a maior presença dessas se concentra embaixo da ponte. Porém, cabe ressaltar que as escritas encontradas na cidade geralmente são assinaturas de pessoas, realizadas principalmente nos pontos de ônibus.

Em Bella Unión (Figura 7 - inferior) fomos recebidos com chuva. O cheiro de terra molhada invadia o ar, anunciando que naquele espaço o asfalto não impermeabiliza todo o solo. Com 20.000 habitantes aparenta maior desenvolvimento do que Barra do Quaraí. Já na entrada da cidade identifiquei pixos de cunho político numa quadra pública de esportes. Entretanto, é na praça central e seu entorno que as escritas urbanas predominam, um local frequentado por adolescentes.

Figura 8: 

e-ISSN 2016/Atual: 2525-7870 | e-ISSN 2015/2016: 2447-018X

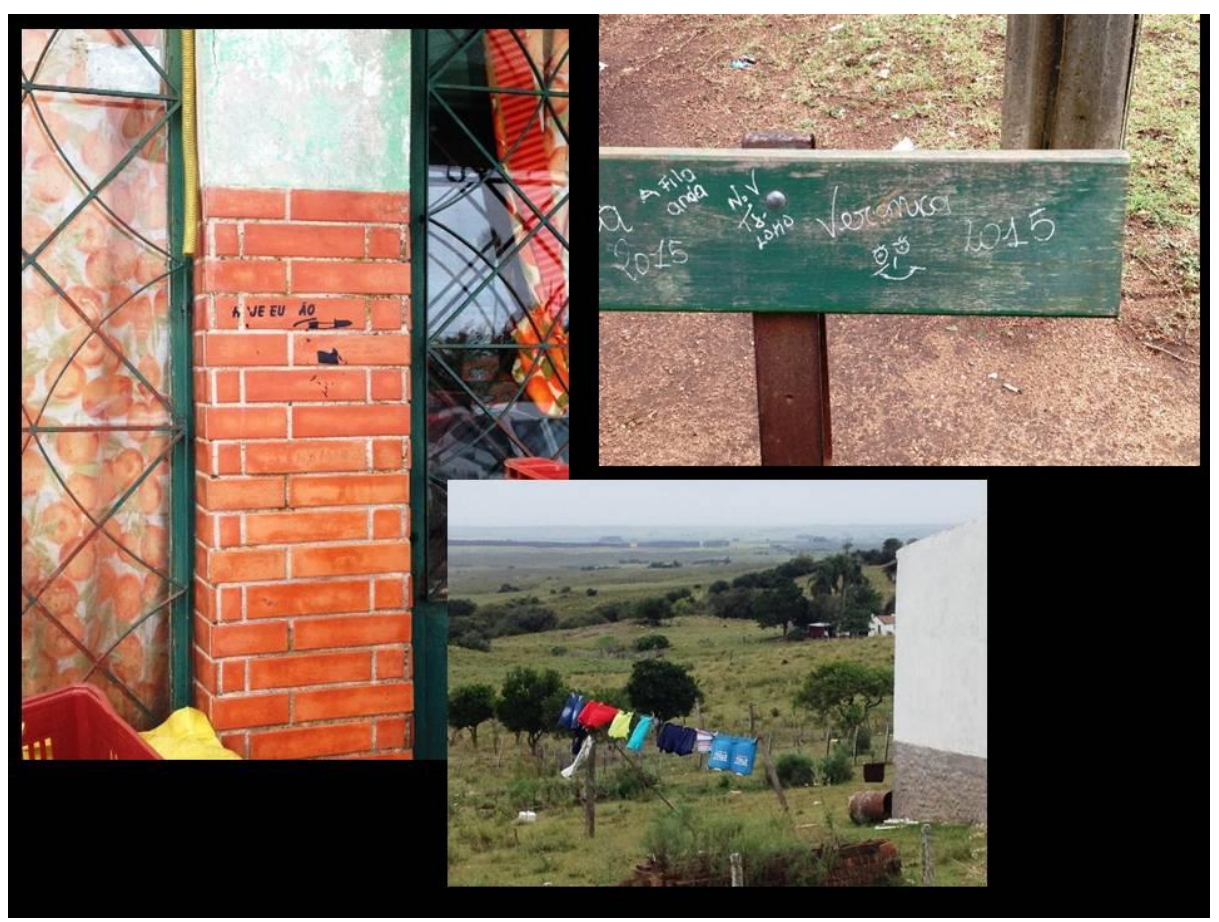

Autor, Aceguá/Aceguá, montagem fotográfica, 2016.

Aceguá/Aceguá quase não se distinguem uma da outra. A fronteira é uma linha imaginária e são as mais rurais de todas as cidades visitadas. Ali Brasil e Uruguai estão unidos e se misturam nas nuvens de poeira que o vento levanta do solo vermelho, de terra batida. Em ambas encontrei somente pequenas marcas, discretos atestados de presença nos bancos da pequena praça e ao lado de uma padaria. Aparentemente somente o vento quebra a rotina desse bucólico lugar, no qual os poucos free shops destoam da paisagem ao redor.

\section{Considerações finais}

Se as escritas urbanas se concretizam como vozes dos anônimos em busca de um protagonismo mais efetivo, será que a sua ausência indicará silenciamentos? Se sim, que forças serão essas, capazes que abafar espíritos inquietos que em outros territórios encontram maior reverberação?

Tais questionamentos não são contemplados com respostas simples. O território da fronteira sempre foi um espaço de controle do estado, caracterizado por tensões próprias que exigem uma discussão mais pontual com base na história de sua constituição. Mas também é preciso considerar que algumas das cidades investigadas são pequenas comunidades, algumas quase rurais, com comportamentos mais conservadores, tradicionais, nas quais tais expressões não encontram lugar para florescer.

Cabe ainda destacar que o maior número de escritas urbanas foi encontrado nas cidades maiores, cuja fronteira é apenas uma linha imaginária, sem separação, como 

e-ISSN 2016/Atual: 2525-7870 | e-ISSN 2015/2016: 2447-018X

Chui/Chuy e Santana do Livramento/Rivera. Essas são cidades mais desenvolvidas, com um comércio mais intenso, e, provavelmente, com um maior nível de educação dos seus habitantes, consequentemente, maior engajamento político. Talvez aí esteja uma possível resposta para a maior presença dos pixos. Entretanto, o que me causou estranhamento é a quase ausência das formas mais artísticas/estéticas, os graffiti. Para esse fato ainda não achei uma provável razão.

Fica assim explícita a complexidade do tema, e o seu cotejamento neste artigo busca apontar algumas respostas possíveis. Frente aos dados angariados conclui que, atualizando permanentemente a discussão sobre a cidade como fruto das relações do ser humano com a paisagem, as escritas urbanas criam diálogos compatíveis com sua situação de transição. Temos, portanto, também a fronteira como um universo de permanência confrontado com a descontinuidade de tais manifestações, dando visibilidade à formação do espaço urbano e a seus mecanismos de reprodução. Elas dialogam com cartazes, placas de trânsito, outdoors, e todas as infinitas grafias que se sobrepõem nas ruas, estabelecendo uma rede comunicativa alternativa e autoral, que revelam, acima de tudo, a presença de indivíduos em busca de significação própria.

Sendo assim, perceber os detalhes, a sobreposição das mensagens, as composições transitórias e a comunicabilidade das inscrições nos fornecem matéria para uma recepção coletiva simultânea e propõem o aprendizado de olhar e repensar o espaço urbano de fronteira de acordo com suas peculiaridades e ritmos/dinâmicas próprios. Logo, também é possível afirmar que refletir sobre o homem e o universo em sua essência, tendo por base os fundamentos culturais, significa valorizar os elementos constitutivos das coisas, reconhecendo que a expressão artística é a exteriorização da existência, uma forma de ação cujos efeitos se produzem de modo indireto.

Seja fomentando o diálogo sobre as relações humanas com o meio, desconstruindo a linguagem, explorando sua potencialidade narrativa ou assumindo um posicionamento diante do contexto nacional, os escritores urbanos definem sistemas de elaboração de realidades, que nos explicitam mentalidades e comportamentos. E aqui cabe ressaltar a importância da fotografia em tal proposta de pesquisa, pois é ela que permite registrar para a posteridade algo que em sua essência é transitório.

\section{Referências}

BERGER, John. Modos de ver. Rio de Janeiro: Rocco, 1999. 

e-ISSN 2016/Atual: 2525-7870 | e-ISSN 2015/2016: 2447-018X

BACHELAR, Gaston. A poética do espaço. São Paulo: Martins Fontes, 1993.

BADERNA, Coletivo. SITUACIONISTA - Teoria e Prática da Revolução/Internacional Situacionista. São Paulo: Conrad Editora do Brasil, 2002.

CANCLINI, Nestor Garcia. Culturas Híbridas. 4ª ed. São Paulo: Edusp, 2003.

GITAHY, Celso. O que é graffiti? São Paulo, SP: Editora Brasiliense, 1999.

PESSANHA, José Américo Motta. BACHELARD E MONET: O OLHO E A MÃO. In: NOVAES, Adaulto et al. O OLHAR. São Paulo: Cia das Letras, 1988, p.149-165.

STAHL, Johannes. STREET ART. Berlim: H. F. Ullmann, 2009.

TACUSSEL, Patrick. PERFIL DE UMA LENDA MODERNA. In: GUTFREIND, Cristiane Freitas; SILVA, Juremir Machado da (orgs). Guy Debord antes e depois do espetáculo. Porto Alegre: EDIPUCRS, 2007, p.11-29. 